\title{
Characterization of 2024-T351 friction stir welding joints
}

\begin{abstract}
Characterization of macrostructure, microstructure, hardness, precipitate distribution, residual stress, and cyclic deformation behavior of 2024-T351 friction stir welded joints has been conducted. Inhomogeneous microparameters governing the nonuniform residual stresses and cyclic strength are discussed. The cyclic strength of the weld microregimes is controlled by grain size and distribution of precipitates achieved during the weld process. The comprehensive information of micro- and macromechanics is used to assist in understanding the mechanism that governed the fatigue crack initiation, propagation, and life of the welded joints. (C) ASM International.
\end{abstract}

Keyword: Manufacturing standards; Mechanical component; Mechanical tests; Weld 